\title{
On Reinventing Education in the Age of Complexity: A Vygotsky-inspired Generative Complexity Approach
}

TON JÖRG

(The Netherlands)

\begin{abstract}
Reinventing education is the ultimate aim of this contribution. The approach taken is a radical new complexity-inspired bottom-up approach which shows complexity as the fount of creativity and innovation. Organizing complexity accordingly may be the foundation for a new complexified vision of education. It all starts with new thinking in complexity about how complexity is actually generated in the real world. Such thinking offers new kinds of complexity like generative and emergent complexity. The approach taken is very much inspired by the genius of Vygotsky, as a visitor from the future. His focus was not only process-oriented, but also very much possibility-oriented. His method was bottomup, and opened new spaces of the possible, like the Zone of Proximal Development. Yet he was not able to deal with the problem of complexity in his days. He 'simply' lacked an adequate causal framework, which showed causation as a generative bottom-up process, to be linked with potential nonlinear effects over time. He could not explain what he saw as possible: the turning points and upheavals of learning and development. In this contribution the focus will be on the link between the new thinking in complexity and the causal, generative nature of complexity in the real world. This link may show the ontological creativity of the entire world in general, and of human learning and development in particular. It may show the power of generativity to unleash this creativity by a new way of theorizing on education. The complexity-inspired theory of development as generative change, as thriving on the generative power of interaction, is fundamental and foundational for this new theorizing.
\end{abstract}

The Russian scholar Lev Vygotsky has been recognized as a genius in his days (Wink \& Putney, 2002, p. xvii), and later been described as "a visitor from the future" (Bruner, 1987). This is for good reasons, as will be shown below. His main focus was on learning and development of children. Yet, he has never been able to offer an adequate scientific view of the complex processes of learning and development (Vygotsky, 1978, Chapter 5). He has never been able to explain the deeply complex nature of the development he described so 
eloquently. His problem of theorizing about the complexity involved in learning and development may now be recognized as "the problem of complexity" (see Cilliers, 1998; Morin, 2008). This is a deep problem that still dominates science and the science of complexity in our postmodern society (Cilliers, 1998). Scholars of our days may be described as (still) being "blind to the problem of complexity" (Morin, 2008, p. 6). This problem has been linked with the so-called 'crisis of knowledge' in the Age of Complexity (Cilliers, 1998, 2013; Jörg, 2014). The knowledge made available in our regular sciences has become the problem itself instead of the solution (cf. Müller-Prothmann, 2006). It may be recognized now that this crisis is still very much the same crisis, as described by Vygotsky in his days (see Vygotsky, 1978, 1997)! This crisis may be ascribed to the very same "problem of complexity" for the sciences, as described above.

So, it may be argued that this problem has largely remained unsolved since his days. The question is how this 'failure' of science in solving the crisis can be understood and explained? It may be argued it is because of the deep misunderstanding about the true nature of complexity. The misunderstanding that you can solve the problem of complexity by a top-down approach. Helga Nowotny (2003) seems very right in her analysis of the deep problem of concern here: that complexity seems still too complex to deal with by our sciences (p. 2). She has described this state of the art of studying complexity as "the embarrassment of complexity" for science in general:

When it dawns on us that the categories we normally use to neatly separate issues or problems fall far short of corresponding to the real world, with all its non-linear dynamical inter-linkages. (p. 1; emphasis added)

It may be understood from this view of the state of the art in science in general why the complexity perspective is "still very much under construction" (see Arthur, 2015, p.90), and not only for economics! It is no surprise, then, that Vygotsky, in his days, had serious problems to deal with the embarrassment of complexity, in developing an adequate scientific view of learning and development. His problems illustrate the deep problem of complexity for our sciences in general and for education in particular. This problem has not only a direct link with the question around the very possibility of education (Hansen, 2015) but also with the mission of this journal (see Davis et al., 2004; and Osberg, 2009).

\section{Vygotsky's Problem}

In general, any fundamentally new approach to a scientific problem inevitably leads to new methods of investigation and analysis. (Vygotsky, 1978, p. 58)

Vygotsky described the 'failing' state of the art in science as a crisis in psychology (see Vygotsky, 1978, p. 5; and Vygotsky, 1997). Based on his analysis of the crisis, he showed a new direction for the social science, i. e. for psychology. Yet, in our view, he has not been able to offer an adequate explanatory framework for understanding the complexity of the causal dynamics of interaction involved in his main study of learning and development of children (Vygotsky, 1978, p. 73). Interestingly, he was convinced that thinking in complexes was very much needed to offer an adequate account of the causal dynamics of interaction (Vygotsky, 1978, p. 62). He noticed correctly that contemporary psychologists "were not interested in complex reactions as a process of development" (ibid., p. 68). He stressed in his description of the study of reactions, in terms of "the dynamic flow of the entire process of its development" (ibid., p. 69), that "the complex reactions must be studied as a living process" 
(p. 69; emphasis added). Yet, he was not able to offer an adequate account of the nature of complexity involved in the living process; that is, as taking place within "the actual causaldynamic relations that underlie phenomena" (ibid., p. 62; emphasis added). In his description of the process, Vygotsky was not able to link the dynamics of interaction with the nonlinear effects he described. He could not make the link between the upheavals, the leaps or turning points in child's development, and the metamorphosis or the qualitative transformation brought about by the interaction among the participants in the very complex process of learning and development (see Vygotsky, 1978, p. 73). Vygotsky did not describe the role of the shaping forces and their (causal) effects on the participants involved in the causal dynamics of interaction. Effects which are linked to the reciprocal influences exerted by the actors on each other: operating causal shaping forces, evolving over time. Vygotsky's central focus was on the development of the child as an individual, thriving on the interaction with others (cf. Follett, 1924/1971, for a different view).

In this contribution we will focus on the true nature of complexity involved in the interaction with others. The fundamental challenge is to explain the potential nonlinear effects of that interaction from a radical new complexity perspective. This is based on a new way of thinking in complexity (Jörg, 2011, 2016). Vygotsky was right that you cannot find such a new way of thinking; you have to invent it (see Vygotsky, 1997)! The true challenge, then, is one of reinventing science in the Age of Complexity (cf. Laughlin, 2005, for physics; and Arthur, 2015, for economics). This challenge is, in our view, very much the challenge for reinventing education in this Age of Complexity too!

\section{The Age of Complexity}

The Age of Complexity may be viewed as a radical new age, in which science is actually in a transition phase (see Nowotny, 2013, p. 2). The Age of Complexity may not only be linked to "opening science" (Wallerstein et al., 1996), but also to "re-thinking science" (Nowotny et al., 2001). It may even be linked to the possibility of "reinventing science" (Laughlin, 2005; cf. Arthur, 2015).

From a historical point of view, science may be viewed as being in a kind of preparadigm period (Kuhn, 1970), as being at the edge of a scientific revolution (Jörg, 2011, 2017). This revolution, we think, is about a new generative bottom-up approach, based on new thinking in complexity about the true generative nature of complexity. The transition involved is the transition of the Age of Reductionism into the Age of Complexity, to be viewed as an Age of Emergence (see Laughlin, 2005). The very generative nature of complexity may open the possibility to explain the very nature of generative emergence (Lichtenstein, 2014). All of this may have promising, unexpected, unanticipated effects for the field of education too. The transition shows the very promise of new thinking in complexity about learning and development as fundamental nonlinear concepts, as thriving on interaction with others (Vygotsky, 1978). This notion of learning and development as complex processes of interaction may open the wondrous world of the possible for education (see Jörg, 2016): not as a risk, but as a complex, deep promise of education (Hansen, 2015). That is, the promise of opening new spaces of the possible. Education may then be taken as being able to innovate itself. We may start to speak about the promise of complexity for education itself, in enabling complex, generative learning in generative education, as a way of open-ended, bottom-up learning (Johnson, 2001, p. 57; emphasis added). It opens "the question of education's possibility and of its realization in life" (Hansen, 2015). This question is directly 
linked with the possibility of "enlarging the spaces of possibility around what it means to educate and to be educated", describing the mission of Complicity (Davis et al., 2004). Opening and enlarging these spaces of possibility may be linked with the opening of very much unexplored territories of complexity for education. This implies the opening of the field of education with a new way of thinking in complexity about the complexity of education itself. It may also open the discussion about the possibility of education in the Age of Complexity (Jörg, 2009, 2016; Hansen, 2015).

\section{A New Generative Complexity Approach}

With our new approach of complexity, we may become able to reveal the unexplored territories of complexity. This may open a new world for the field of education: the world of the possible. First, we need to recognize that we are in a kind of so-called 'pre-paradigm period' (see Kuhn, 1970), with scholars of all kind, 'waiting' for a new science to arrive. A new science, which may be based on the new paradigm of complexifying (Morin, 2008). This new paradigm may open a new generative complexity approach for science (Jörg, 2011, 2016, 2017). This new approach may be conceived as a fundamental and foundational bottom-up approach (see Holland, 1995, 2014). We may need to start a new way of thinking, so to become able "to reinvent science from the bottom down" (Laughlin, 2005). This reinvention of science itself may bring with it the possibility of reinventing education, and to open "the space of education" (Hansen, 2015) for all. Opening this space as a "wondrous world of the possible" (Jörg, 2016) may be conceived as opening a future world of education.

The new paradigm of complexifying may open the complex world of new spaces of possibility: that is, a world of unlimited possibilities (Maturana, 1980). This is opening and enlarging the field of education. That is, the very possibility of education in the Age of Complexity: by "enlarging the spaces of the possible around what it means to educate and to be educated" (Davis et al., 2004). It may be shown how a new complexity-inspired bottom-up approach may be foundational for opening the unexplored path of 'imagineering education' in the Age of Complexity (i.school, 2016), with imagineering as "a complexity-inspired design approach" (see Nijs, 2014). This approach may take into account the role of the so-called 'adjacent possible', all for the sake of opening the new spaces of learning and development. These new spaces may now be conceived as generative spaces, such as the 'Zone of Generativity' (Ball, 2009, 2012ab; Jörg, 2016), and the even more complex, multi-dimensional 'Space of Generativity' (Jörg, 2016). The aim here is to show a way to open these new complex spaces of generativity for education. This may be enabled through new thinking in complexity about the complex processes of dynamic interweaving within dynamic unities of learners and the dynamic processes of dyadic interaction (Jörg, 2011, 2016; Caporael et al., 2014. These processes are thriving on the full generative power of interaction (see Bruner, 1996). The complex nexus of interactions, with their generative power, may now be linked with the complex web of relationships, operating as catalysts of novelty and innovation (see Goldstein et al., 2010, p. 2). They may as well be viewed as catalysts for the nonlinear effects, described by Vygotsky (1978): effects like turning points and upheavals (p. 73).

\section{Understanding the Dynamics of the Nexus of Interaction}

Vygotsky faced the fundamental problem of understanding and explaining the "causal dynamics of interaction", and of the nonlinear effects he described as actually possible (see 
Chapter 5, in Vygotsky, 1978). In our view, he had great problems to make this link. He not only lacked an adequate causal framework to model his description of the causal dynamics of interaction as a complex process of nonlinear interaction. He also had problems to recognize and explain the very generative nature of the causal dynamics involved in the interaction. He had problems to explain the nonlinear nature of the (total) causal effects involved in the process of interaction. He did not describe the interaction as a process of reciprocal influencing with dynamic interweaving, taking place within a web of relationships, like others have done (see Mary Parker Follett, 1924/1971; and Bohm \& Peat, 2000, p. 194). Follett (1924) actually faced the same complex problem as Vygotsky: of explaining the true nature of the causal dynamics of interaction. Follett fully recognized the need for what she described as "the functional theory of causation" (Follett, 1995, p. 53). This theory encompasses the process of reciprocal causation (see Arthur, 2015, p. 94), involved in the dynamic unit of reciprocality of interaction (Caporael et al., 2013). In the days of Follett and Vygotsky, no adequate causal framework was available. So, no calculus was available to account for the nonlinear effects of the causal dynamics of interaction. These effects are linked to the complex process of causation, taking place in the process of dynamic interweaving between the actors involved:

my changing activity is a response to an activity which is also changing; and the changes in my activity are in part caused by the changes in the activity of that to which I am in relation and vice versa (Follett, 1995, pp. 42-43; emphasis added).

To put it differently:

while I am behaving, the environment is changing because of my behaving, and my behaviour is a response to the new situation which I, in part, have created (ibid., p. 42; emphasis added).

So, Follett fully recognized not only the complexities involved in interaction, but also the opening of spaces of possibilities by the actors involved in the causal dynamics of interaction, as being enabled by the complex dynamic process of interweaving within relations.

To fully understand and explain the causality involved in the causal dynamics of interaction is a complex problem indeed (see Jörg, 2011, 2016, 2017). It is of importance to understand that, with the science-as-we-know-it, and the causal framework-as-we-know-it, it will not be possible to understand and explain the nonlinear effects of the causal dynamics of interaction (cf. Grotzer, 2012). It will not be possible to understand the complexity involved in causality: that is, of causation as a generative process (see Jörg, 2011, 2016, 2017). We need a new generative lens to see the new possibilities (Jörg, 2017).

The message to be derived from the above is that we urgently have to learn causality in a complex world (see Grotzer, 2012). We have to learn causality anew, as complex causality, involving forms of causality like mutual causality, cyclic causality, relational causality, and spiral causality (see Grotzer, 2012). All of these forms of causality actually describe what we are very much missing in understanding the complexity of causal dynamic interaction. We may then better understand why "we are running against the hard wall of complexity" (Barabasi, 2003, p. 6). In our view this is the main reason why "we are still blind to the problem of complexity" (see Morin, 2008, p. 6). We 'simply' have no tools and method to understand the very generative nature of causality and to understand causation as a fundamental generative process: as a process of self-causation (Jörg, 2011, p. 150; cf. Goldstein et al., 2010, p. 3). It may therefore be well understood that the framework of causality, like the 
complexity perspective, is "still very much under construction" (Arthur, 2015, p. 90). It should be clear by now that we need a new causal framework about the causal dynamics of interaction. Only then we will become able to understand the true generative, emergent nature of complexity.

In regard to the state of the art in science, it seems to be the case that scholars of science are not missing what they are actually missing most: a new account of causality as nonlinear causality (Juarrero, 1999). They do not seem to miss a scientific account of causation as a (self-) generative process with potential nonlinear effects of strengthening over time. They actually do not seem to miss a causal framework of nonlinear causality, needed to account for a truly complex world: that is, a complexly generative world. This is a world with generative complexity, emergent complexity, of complexity as bootstrapping complexity, and of complexity as self-potentiating and self-sustaining (Jörg, 2017). A world with complexity, with systems operating with the complex capacity of perpetually inventing themselves (like economy; see Arthur, 2015, p. 25). It may be understood and should be understood that we urgently need new kinds of complexity, so to become able to offer a radically altered account of the very complexity of reality (cf. Kauffman, 2009, p. xv). The new kinds of complexity, linked with emergence, may "offer a key to new kinds of understanding" (Holland, 2014, p. 5): that is, of understanding the world as a complex generative world. A world in which "the interactions of interest are nonlinear" (ibid., p. 4; italics in original). A world in which socalled 'bottom-up' effects (ibid., p. 5) have their place, as a result of emergence, thriving on the full generative power of interaction. A new, much more complex world, showing a different kind of possibilities for education, in opening and enlarging the spaces of possibility for education, like the multi-dimensional Space of Generativity (Jörg, 2016, 2017). This new complex space may be taken to be a very complex concept, of relevance for education.

\section{A Complex Causal Framework}

Below, we will sketch a short overview of the complexity of causal dynamics of interaction (see Jörg, 2011 and 2016, for a more complete sketch of the framework). The causal dynamics is taking place in the interaction between two actors or entities, with their so-called 'latent variables' linked to them: see Figure 1 below for the simplest view of this interaction. This figure represents mutual causality, with interaction as mutual causal processes, which "is used in many disciplines" (Milsum, 1968, p. 23; see also Maruyama, 1968). The key in understanding the causal complexity involved in mutual causality is to be found in understanding the generative nature of causality and of causation as a generative process; that is, as being operative as reciprocal causation within reciprocal relationships between entities.

We may understand the unit of two entities involved in interaction as a so-called 'selfgenerative unity' (Jörg, 2017; cf. Whitehead, 1978, p. 47, on a 'self-creative unity'). The change involved may be linked with "self-generating social change" (Maruyama, 1968, p. 96, in social and cultural evolution; cf. Keller, 1985, p. 132). It is important to understand the complex dual nature of the loop as a self-generative unity, with two entities / actors, and their different causal influences and their corresponding direct effects on each other. The interaction takes place within a reciprocal causal relationship, with the relationship between $\mathrm{A}$ and $\mathrm{B}$ being different from the relationship between $\mathrm{B}$ and $\mathrm{A}$ ! 


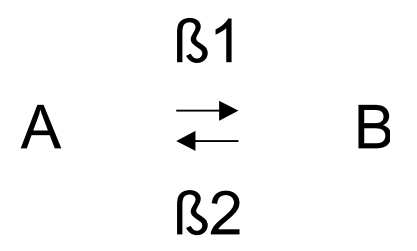

Figure 1. A structural model of causal interaction between so-called 'latent variables', with corresponding parameters of direct causal effects

Not only the direct causal effects on each other are different, but also the total causal effects on A and B. These total effects are composed of the direct causal effects, the loop effect, and the indirect effects (see Jörg, 2011, 2016). The loop effect may be described as a geometric series as follows:

$$
B_{1} * \beta_{2}+\left(B_{1} * \beta_{2}\right)^{2}+\left(\beta_{1} * \beta_{2}\right)^{3}+\ldots \ldots . .\left(\beta_{1} * \beta_{2}\right)^{n}
$$

The geometric series may be re-described as:

$$
\left(ß_{1} * \beta_{2}\right) / 1-\left(ß_{1} * \beta_{2}\right) .
$$

This is the case if the absolute value of the product of $\beta_{1}{ }^{*} \beta_{2}$ is smaller than the value 1 (see Jöreskog \& Sörbom, 1993, p. 154). This loop effect may be conceived as a so-called 'multiplier effect' (see Milsum, 1968, p. 64; and Holland, 1998, 2014). The loop may be called a 'multiplier loop' (ibid., p. 64). The loop effect, as a multiplier effect, may increase over time in a non-linear way (ibid., p. 65), with increasing values of the two beta's. The loop effect is actually the key for understanding the very nonlinear nature of causality and of reciprocal causation, with the corresponding potential non-linear effects over time. Emergent causality, in turn, may be taken to be the key for understanding complexity as generated over time: that is, for understanding generative complexity (Lichtenstein, 2014).

It is of importance to understand that the total effects on A and B are actually generated in and through the "causal dynamics of interaction" (Vygotsky, 1978). The functions of the total effects may be understood as generative functions, descriptive of how causal effects on A and $\mathrm{B}$ are actually generated in the complex process of reciprocal causation. These functions may also be understood as so-called 'transition functions', descriptive of future possibilities and states of A and B as complex entities (cf. Holland, 1998, p. 128). The total causal effects on A and B may now be understood as emergent effects, generated over time, being descriptive of "transitions from state to state" (Holland, 1998, p. 128). The underlying dynamics can be viewed as generative emergent dynamics. The formulae of the total causal effects of the causal dynamics of interaction may be viewed as expressing "a new kind of law" (Kauffman, 2013, p. 188): a law expressing the dual potential nonlinear effects of the causal dynamics of interaction. This law may explain what Kauffman describes as "the emergence of complexity" (ibid., p. 188; emphasis added). This law may now be called "the Causal Law of Emergence" (cf. Kauffman, 2013, p. 188; emphasis added). It actually describes the dual effects of the causal dynamics of interaction. This new law may finally explain how complexity is actually generated in a complex world: as operating in a dynamic network of interconnected (causal) loops. From this conclusion, we may also understand why "[T]he complexities introduced by loops have so far resisted most attempts at analysis" (Holland, 2014, p. 39; emphasis added). 
We may also understand why "we don't understand the behaviour of cyclic neural networks very well" (Holland, 1998, pp. 20-21).

The complexity of the causal effects within cyclic networks, operating through multiplier effects, may be viewed as the fundamental and foundational key for connecting causal complexity with the new kinds of complexity, like generative, emergent complexity in dynamic networks of interconnected loops. This is opening new spaces of the possible within unknown territories of complexity, hitherto still very much unexplored. This may finally "reveal a new world" (Arthur, 2015, p. 25): also for the field of education!

With the Causal Law of Emergence, described above, we can finally explain how causal complexity may develop into generative, emergent complexity in this complex world. This strongly supports Holland's conclusion that "generated complexity is essential to emergence" (Holland, 1998, p. 76; emphasis added). We think he is right in his view that "we will have to look at it closely if we are to understand emergence" (ibid., p. 76; emphasis added). His view about the very generation of complexity from simple specifications is daunting indeed "because it assures that complexity will be pervasive in the world around us" (ibid., p. 76).

It may be concluded that the new framework of causality opens up a new way of explaining complexity in the real world, being operative as a complex generative world. It may also show how complexity can operate bottom-up in this generative world: through the generative emergent dynamics of causal interaction within reciprocal relationships. This complex dynamics is operating as emergent causality in the causal dynamics of interaction. This complex dynamics may now operate as deviation-amplifying dynamics (Maruyama, 1963; Jörg, 2011). The underlying mechanisms are very much generative, amplifying mechanisms. They are foundational for the conception of a new theory of generative change for education (cf. Ball, 2009), which is opening new spaces of possibility, with unexpected and unanticipated nonlinear effects over time. The theory of generative change may now be understood as a complexity theory of emergence: that is, a theory of 'generative emergence' (Lichtenstein, 2014). We may finally learn to use a generative lens to see the generative emergence, being operative in the real world as a generative world, enabled through generative change, and thriving on the generative process of causation, with its emergent causal effects.

\section{Multiplier Effects}

Interestingly the direct causal effects on A and B in Figure 1, which may have different values between 0 and 1, may take place in the interaction simultaneously (cf. Grotzer, 2012). The loop effect, however, is symmetric and the same for A and B! The loop effect may be described as a so-called 'multiplier effect' (see Holland, 1995, p. 25; and Holland, 2014, p. 68). The total effects, however, encompassing the symmetric loop effect, are not symmetric! It may be concluded that the loop effect and the total effects show an unexpected complexity. A and B may actually strengthen the total effects on each other, by increasing the direct effect on the other. The result of this increase may be understood as a complex, generative process. This describes the complexity of the generative change involved in the causal dynamics of interaction. This notion of complex, generative change can be linked to complexity as linked to a web of interactions "bootstrapping itself upward over time" (Arthur, 2015, p. 146; emphasis added). This complex process of bootstrapping may be taken to be the key for understanding complex processes of "bootstrapping each other" in interaction (Bruner, 1996, 
p. 21). This effect corresponds with the so-called 'Matthew effect': "the rich get richer and the poor get poorer" (see Jörg, 2009, 2016).

It may as well be shown that A and B may also strengthen the total causal effects on themselves over time: by increasing the causal influence and the corresponding causal effect on the other. This may happen even if the direct influence of the other actor / entity on themselves keeps constant (see Jörg, 2011, 2016)! This effect may be conceived as the 'Comenius effect': "he who teaches others, teaches himself (see Gartner et al., 1971, pp. 14-15; Jörg, 2016). This effect may be conceived as a process of so-called "self-bootstrapping" (see Arthur, 2015, p. 155). This process of self-bootstrapping may be linked to the emergence of a system or entity like the child as a complex learner "learning to program itself" (Arthur, 2015, p. 155). This notion can easily be linked to Vygotsky's view of the child becoming the master of his / her own learning and development (see Vygotsky, 1978, pp. 51, 73).

The simple model, sketched above, of the causal dynamics of interaction between two actors / entities, operating as reciprocal causation within their reciprocal relationship, may illustrate the unexpected complexity of nonlinear (total) effects of interaction, with the multiplier effects involved.

It may be concluded that generative emergent complexity can be grounded in causal complexity, operating as nonlinear causality within loops; that is, operating within the unit of two entities in interaction, to be conceived as a self-generative unity (Jörg, 2017). This conclusion strongly supports the view of Grotzer (2012): that we have to learn causality in a complex world. Causality and causation shows to be much more complex than scholars of all kind have assumed in the history of science.

We may finally become able to learn causality and causation as being part of a new "bottom-up paradigm" (Johnson, 2001, p. 67). We may learn a "bottom-up style of thinking" (Axelrod \& Cohen, 1999, p. 29), as a new mode of thinking (ibid., p. 28), so to become able to understand the unexpected, complex processes of change as complex, generative change. We may learn causality in a complex world, to become able to learn how emergence may actually operate in the real world (Arthur, 2015, p. 155), thriving on the causal dynamics of interaction as a complex, generative process of causation. We may finally learn how generative emergent complexity may be embedded and operate in a world which is "fundamentally different from that which has previously characterized modern science, with its emphasis on prediction and control" (Solé \& Goodwin, 2000, p. 28).

Based on the new understanding of generative, emergent complexity, we may understand learning and development anew, being operative in a complex, generative world. A world which has remained very much unknown, also for those involved in theorizing on development and education.

\section{Understanding Learning and Development Anew}

Vygotsky's conception of development is at the same time a theory of education.

(Bruner, 1962, p. v; emphasis added)

The causal dynamics, described above, may now be linked to the causal dynamics of interaction involved in learning and development, as sketched by Vygotsky. This may include the potential nonlinear effects as conditional for effects such as turning points, upheavals, and qualitative transformation or metamorphosis (see Vygotsky, 1978, p. 73). The complexity involved may be viewed as evidence for the view that development plays a 
special but undertheorized role in science (cf. Caporael et al., 2014 p. 15). Not only in "accounts of biological evolution, cognition, and cultural change" (ibid., p. 15), but also in accounts of development in the field of education. It may be understood by now why Vygotsky had a hard problem to explain "the highly complex relations between developmental and learning processes" as complex dynamic relations (Vygotsky, 1978, p. 91). This problem may be recognized as the hard problem of complexity (cf. Barabàsi, 2003, p. 6). It is the problem of linking the effects of learning on the development of children with nonlinear effects. This problem is still a hard problem for theorizing on development and education. According to Paul van Geert, it is still "completely unclear what teaching and learning entail if conceived at the level of specific activities and processes" (see Van Geert, 1994, pp. 247-248; emphasis added; cf. Vygotsky, 1978, p. 57).

The causal effects, linked to the description of nonlinear causality and causal emergence above, may be taken as foundational for a way of re-describing the description of nonlinear effects of learning and development. They are fundamental and foundational for a new theory of change: that is, of a so-called "theory of generative change" (Ball, 2009). A theory which Ball has linked with the complex concept of 'Zone of Generativity', derived from Vygotsky's concept of the 'Zone of Proximal Development' (see Ball, 2009, 2012ab; cf. Bruner, 1996, p. 76, on children, generating the Zone of Proximal Development). We may now better understand the true nature of generative change by our new complexity perspective. Generative change may now be understood as enabled by the self-enhanced loop effects, being operative within the causal dynamics of interaction. These loop effects operate as multiplier effects, thriving on the multiplicative generative nature of causal interaction. This generative nature is opening for the description of the full generative power of interaction, being operative within the causal dynamics of interaction (cf. Bruner, 1996).

The new theory of generative change may now be linked to complex, generative processes of learning and development, thriving on interaction in both intra- and inter-personal processes (Vygotsky, 1978). The theory may as well be linked to the complex dynamic interweaving of these generative processes and their generative outcomes over time. These generative processes are thriving on the full generative power of interaction (Bruner, 1996). The total causal effects of this interaction may now be understood as emergent 'bottom-up' effects, generated in non-linear interactions (see Holland, 2014, pp. 4-5). These total causal effects, thriving on the non-linear nature of causal interaction, may now be linked in a new way to the known concept of 'Zone of Proximal Development' (ZPD), introduced by Vygotsky (1978, p. 84). This Zone may be viewed as descriptive of "bottom-up effects" (Holland, 2014, p. 5; cf. Johnson, 2001). Very much in line with this view, Vygotsky was of opinion that "an essential feature of learning is that it creates the zone of proximal development" (p. 90; emphasis added; see also Bruner, 1996, p. 76, on children generating their own ZPD). Vygotsky adds to this: “learning awakens a variety of internal developmental processes that are able to operate only when the child is interacting with people in his environment and in cooperation with his peers" (p. 90; emphasis added).

The renewed concept of the ZPD may thus be described as a (very) complex concept, to be linked to the concept of 'the adjacent possible' (Kauffman, 1993, 2003; see also Loreto et al., 2017). Every change in the shaping causal forces exerted by the actors in interaction may trigger a generative, deviation-amplifying mechanism which may bring about nonlinear (total) causal effects on the actors involved. These effects take place over time, without being dependent on time as a variable. These effects are a result of their interaction over time, taking place within their mutual, dynamic reciprocal relationship (Jörg, 2011, 2016). The 
corresponding mutual effects of the causal dynamics of interaction may also be linked to socalled 'multiplier effects' of this interaction (Holland, 1998, 2014; Jörg, 2011, 2016). From this complex notion, we may better understand Vygotsky's theory: that it is through interaction with others, through cooperation with others and with peers, that we may develop into ourselves (see Vygotsky, 1978, p. 90): that is by opening and enlarging new spaces of possibility, like the Zone of Generativity and the Space of Generativity.

\section{Opening New Spaces of Possibility for Education}

From the nonlinear effects of causal interaction within dynamic loops and the corresponding multiplier effects, we can now make a link with the concept of 'generativity' as a complex network-concept. We may conceive of generativity as thriving on the connectivity and interactivity of the network of dynamic, interconnected loops involved (Jörg, 2017). This description of generativity may show the power of generativity to generate the nonlinear multiplier effects: that is, through non-linear interactions within networks of dynamic, interconnected (causal) loops (cf. Holland, 2014). This is enabling for viewing generativity as a complex, multi-dimensional concept, to be linked with this self-generative unity. A concept which may be understood as closely connected to the concept of creativity (cf. Whitehead, 1978, p. 47, on the 'self-creative unity'). This is opening for a new way of thinking, of thinking in complexity, about the opening of new spaces of possibility, like the Zone of Generativity and the even more complex, multi-dimensional Space of Generativity. These new spaces may now be taken as complex generative spaces of possibilities for education (see Fels, 2004, p. 76). Interestingly, the concept of 'generativity', originally conceived by the psychologist Erik Erickson (1950; see Bushe, 2013), has recently been described:

- $\quad$ as the power to create (Stepper, 2014, p. 1)

- the power that brings individuals into being [and] in great part sustains them without their choice or deliberate effort (Sassone, 1996, p. 519)

- the power of constituting the individual directed by that individual to becoming a being in-and-for-self (ibid., p. 519)

We may derive from this description that generativity can be linked to creative forces and power. The complex creative power of generativity may now be understood as thriving on the complex generative power of interaction between learners, with generativity itself conceived in a complex way, as being about

- the processes and capacities that help people see old things in new ways (Bushe, 2013, p. 2; emphasis added)

- the cause and effect of individualization (Sassone, 1996, p. 519; emphasis added)

- $\quad$ self-sustaining (Stepper, 2014, p. 2)

The creative, generative power of generativity may now be understood as the complex, generative motor of generative change. A generative motor which is operative in the complex generative dynamics of dynamic interweaving of learners and the corresponding intrapersonal and inter-personal processes of these learners in their interaction (see Vygotsky, 1978; and Follett, 1924, 1995). These processes may now be taken as being "both interindividual and intra-individual processes" (Sassone, 2002, p. 122). The learners are not only entities or agents being involved in a complex process of inter-action, but also as entities-inprocess themselves, as a complex process of intra-action. This makes the whole dynamic unit so dynamic and unexpectedly complex indeed (cf. van Geert, 1994), also in the description of 
the complex, dual effects on both learners in their interaction over time. We may now start to think in a different way about theorizing education, by questioning education anew, in terms of education's possibility (see Hansen, 2015). This may show the very complexity of education in the Age of Complexity. The hard problem of complexity, then, can be linked to the hard problem of education itself.

\section{On the Question of Education's Possibility}

the greatest and most difficult problem to which man can devote himself is the problem of education (Kant, in On Education, 2003 / [1899], p. 11)

Kant was of opinion that the problem of education is a hard problem indeed (see quote above). More recently, David Hansen has put the fundamental question about education in terms of "the possibility of education" (Hansen, 2015; emphasis added). This question has a direct link with the mission of this journal, formulated in 2004, at the start of this journal: "to enlarge the spaces of possibility around what it means to educate and be educated" (Davis et al., 2004; emphasis added). Questioning the very possibility of education may be taken to be a deep underlying problem for education itself! So, the question is still very much open, still waiting for an answer. The challenge that faces us in the Age of Complexity is to re-think education, with the possibility of "a transformation of education" (Nilsook et al., 2014, p. 17). This possibility may ultimately lead to the possibility of reinventing education "from the bottom down" (cf. Laughlin, 2005, on physics)!

To answer the question of education's possibility, and the possibility of reinventing education in the Age of Complexity, we need to think about a new complexity perspective (cf. Arthur, 2015, p. 90). We want to argue here that we may find the answer in the new concepts of 'generative complexity' and of 'emergent complexity' (Jörg, 2011, 2017). These new concepts may describe "the enhancement of complexity as a fact of life" (Rescher, 1998, p. 6; emphasis added). This enhancement may also become a fact of education: by opening education's possibility for the field of education itself. For sure, this demands for a new way of theorizing on complexity and on education: that is on the complexity of education itself. This theorizing may have consequences for organizing complexity in education as the fount of creativity, thriving on the full generative power of interaction. This new theorizing may open new spaces of possibility for education, like the Zone of Generativity, and the Space of Generativity. Inspired by Vygotsky's view on learning and development through interaction with others, we should find ways to handle interaction (cf. Arthur, 2015). All of this new theorizing on complexity puts the very possibility of education in a fundamental new perspective in the Age of Complexity. The world of education may actually be turned into a different world: that is, a complexly generative world. We need a new lens, a generative lens (see Wink \& Putney, 2002, p. 11, on the vision of Vygotsky). We need new theorizing, both on development and of education. We may see new, unexpected and unanticipated possibilities by looking at the world in new way (cf. Laughlin, 2005, for physics). In our view this is the true challenge for education in the Age of Complexity.

We urgently need a different, much more complex description of learning and development for education. For sure we need our imagination for that. With the help of Einstein's insight in the role of imagination, we should become aware that "[I]magination is more important than knowledge. For knowledge is limited to all we know, while imagination embraces the entire world" (in Nilsook et al., 2014, p. 14). So, we need to start theorizing education, opening the possibility of re-describing our description of education by 
the use of our imagination. The challenge for education, then, may be best described as "Imagineering education" (i.school, 2016), as a way to 'solve' the hard problem of education in the Age of Complexity. For sure, this will not be easy. We urgently need our imagination to reveal a new world of education for the future of education. The true challenge is to reveal a new wondrous world of the possible world for education: that is, a complex world of unexpected possibilities (Jörg, 2016, 2017). Of course, this is a hard and complex problem. The complexity perspective itself is also still very much under construction (Arthur, 2015, p. 90; see also Barabàsi, 2003).

\section{A New World for Education?}

Nobody knows what the adjacent possible space looks like and even conceptually it is not clear which tools one could possibly adopt to chart it (Loreto et al., 2017, p. 79; emphasis added)

Thinking about the very possibility of education from a new complexity perspective, with a new vision of complexity as generative, emergent complexity, may be of help "to reveal a new world" for education. Henceforth we may think of education in a radical new way: as taking place through a discursive practice and dynamic process of interaction and of dynamic interweaving within web-like units, like the dyadic self-generative unity. That is, a discursive practice "that reveals the structure and contents of individual's lives to themselves" (Sassone, 1996, p. 516). The dynamics of interweaving may be taken as a very complex process, thriving on the interaction within relations with others (Vygotsky, 1978). The complex, generative processes of becoming, thriving on the generative power of interaction, may then be viewed as fostering "the emergence of a self-observational mediating self for each individual" (Sassone, 1996, p. 516; emphasis added). Based on this complex view, we may better understand the power of generativity as a kind of complex, creative power, being operative in the processes of coming into being through complex generative processes of becoming.

Based on Sassone's understanding of the complex processes involved in development, we may now become able to understand the very generative, emergent complexity involved in Sassone's description of development, in terms of "one makes oneself through one's generativity" (ibid., p. 520; emphasis added). This complex process is enabled through the complex power of generativity. A power which is thriving on the full generative power of interaction within relations with others (Vygotsky, 1978). This creative, generative power of generativity is opening for a fundamental re-description of education: of what it means to educate and to be educated. A re-description which is opening for a radical reinvention of education. This reinvention of education may be linked with the enlarging and the opening of new spaces of possibility. The enlarging of these spaces may also be linked with the concept of "a dynamic generative space of possibilities" (Fels, 2004, p. 76; emphasis added). These generative spaces can be linked with the complex concept of the 'Space of Generativity' (SoG). This may be done by linking the 'space of interaction' (Fels, 2004, p. 80) with the so-called 'adjacent possible space' (Loreto et al., 2017, p. 79). Interestingly, Loreto et al. are of opinion that "[N]obody knows what the adjacent possible space looks like" (p. 79). These authors are convinced that "it is not clear which tools one could possibly adopt to chart it" (ibid., p. 79). They describe the need for "a deeper understanding of the different nature of triggering events along with the signatures of the adjacent possible at the individual and collective level" (ibid., p. 79; emphasis added). 
All of the changes, described above, may be conceived as opening radical new ways of thinking in complexity about education's possibility itself (Hansen, 2015). It shows the deep link between theorizing development and theorizing education (cf. Vygotsky's view above). This new way of thinking is bottom-up, being an essential part of the new paradigm of complexifying. The effects of the interaction within the space of interaction may show for instance the possibility of 'generative emergence' (Lichtenstein, 2014). The space of interaction may then be taken to be triggering complex generative spaces of possibilities, enabled through interaction. The opening and enlarging of these spaces is thriving on the full generative power of interaction. The most important challenge for education in practice, then, is to create these spaces as new spaces of opportunity for learners. The new Spaces of Generativity (SoG) may show the unanticipated possibilities and potentialities for learners: of learners bootstrapping each other upward into their individual SoG (cf. Bruner, 1996). Such bootstrapping may show the potential increase of generativity as a very complex capability of learners: of knowing how to go on (see Lord, 1994)

The new description of education may show the very possibility of enlargement of the cognitive domain as unlimited (see Maturana, 1980, p. 38). This unlimited possibility of enlargement as an un-anticipated, very complex possibility for education, is possible through the complex, generative, emergent processes of coming into being through generative, emergent processes of becoming. This complex possibility for education can be linked with Maturana's description of the dynamics of interaction:

We can say that every internal interaction changes us because it modifies our internal state, changing our posture from which we enter into a new interaction (Maturana, 1980, p. 39; emphasis added).

This new interaction, in turn, takes place in new relations:

As a result new relations are necessarily created in each interaction and, embodied in new states of activity, we interact with them in a process that repeats itself as a historical and unlimited transformation (ibid., p. 39; emphasis added).

This description of dynamic interweaving, thriving on interaction within created relations, may show in what way a theory of development may be taken as a theory of education, as inspired by Vygotsky's way of theorizing (Bruner, 1962). A new theory, to be based on a new theory of generative change, thriving on the generative power of interaction within relations with peers. A theory which may ultimately lead to the transformation of education. We go deeper into this below. First, we want to make the link with Vygotsky's way of thinking as a fundamental bottom-up style of thinking (cf. Axelrod \& Cohen, 1999, p. 29).

\section{The Position of Vygotsky}

From the above re-description of education, we may better understand Vygotsky's position about learning and development (L\&D). A position which is based on interaction within relations with the other. Vygotsky was of opinion that it is through interaction with others that we develop into ourselves. The development is taking place within the ZPD as a created space, as a result of learning in and through that interaction. Although Vygotsky conceived of nonlinear phenomena like turning points, upheavals etc., he did not describe how the mechanisms and dynamics involved were actually being 'at work' in the interaction. Yet, he was convinced of the need to take a radical different approach of learning and development, 
by adopting a radical different method (see Vygotsky, 1978, Chapter 5). His method was inspired by Wundt's description of the complex role of stimuli "that generate a change in the psychological process linked to them" (Vygotsky, 1978, p. 59; emphasis added). Vygotsky's method may in general be described as a way of analysis focusing on:

- The process instead of the object;

- Explanation versus description; and

- Dynamic analysis of development that returns to the source

(in Vygotsky, 1978, pp. 61-65; all emphasis added).

The result of the corresponding dynamic analysis of development will be "a qualitatively new form that appears in the process of development" (ibid., p. 65; emphasis added; cf. Fels, 2004, p. 79). Vygotsky's description of his method of analysis of development shows the main characteristics of the new science of complexity, advocated in Jörg $(2011,2016,2017)$.

Vygotsky actually wanted to invent a new science as a response to the state of the art in his days, but, although he clearly saw the importance of interaction for L\&D, he did not recognize the generative nature of the dynamics of interaction, operating within the scaffolding generative relationships involved in that interaction. He did not describe very well how to foster L\&D and the nonlinear effects of interaction, described by him (Vygotsky, 1978 , p. 73). In his description of method he did not link the causal dynamics with an adequate framework of causality: a framework which could show the very nonlinear nature of causality operating in the complexity of the causal nonlinear dynamics of interaction. This demands for a new way of thinking about causality and of causation. The causal dynamics to be conceived from a new complexity perspective may involve "self-generated enhancement" (Holland, 1998, p. 13; emphasis added), enabled through self-enhanced causal loop effects, and the presence of spiralling causality (Grotzer, 2012). These effects are being operative in the developmental processes, proceeding in a spiral: "passing though the same point at each new revolution while advancing to a higher level" (Vygotsky, 1978, p. 56). Based on this new understanding of spiral development, enabled through the causal, generative dynamics of interaction, being operative within the interpersonal reciprocal relationships, it may be understood that "[A]ll the higher functions originate as actual relations between human individuals" (ibid., p. 57; emphasis added). Vygotsky's description gets close to the complex, dynamic process of interweaving within a dyadic unit, described above.

\section{New Mode of Thinking}

The new ways of thinking in complexity about the new kinds of complexity, sketched above, may be taken as foundational for a new way of thinking about the mission of education in the Age of Complexity. This will be opening up the unexpected possibility of reinventing education from the bottom down (cf. Laughlin, 2005, for physics; Holland, 1998; Johnson, 2001; and Arthur, 2015, for economy). This reinvention of education may be based on a new generative bottom-up approach of complexity, with corresponding 'bottom-up effects' (Holland, 2014, p. 5), like the self-enhanced loop effects (see above), enabled through selfgenerated enhancement (cf. Holland, 1998, p. 13). These bottom-up effects are potentially nonlinear over time (see above). The new generative bottom-up approach may be based on the paradigm of complexifying, to be taken as a new fundamental and foundational "bottom-up paradigm" as one, which is beginning to emerge (Johnson, 2011, p. 67; and Kelly et al., 2016, p. 52). This new approach replaces the top-down approach still dominating the 
science-as-we-know-it. Living in the Age of Complexity, time has come to replace the Age of Reductionism into the Age of Complexity, to be taken as the Age of Emergence (Laughlin, 2005). This age may now be viewed as the Age of Generative Emergence (cf. Lichtenstein, 2014). The complexity of generative emergence can be based on a new theory of generative change. This theory may be based on the complex, generative model of causal dynamics of interaction within relations, sketched above and elsewhere (Jörg, 2009, 2011, 2016). The theory of generative change is very much possibility-oriented, based on a process-oriented approach of learning and development. This theory and approach may be derived from Vygotsky's radical approach of dynamic analysis as his method, being fundamentally process-oriented, bottom-up and explanatory, so "to reveal the actual causal-dynamic relations that underlie phenomena" (Vygotsky, 1978, p. 62). These are phenomena like turning points, upheavals, leaps, and qualitative transformation or metamorphosis (ibid., p. 73). These phenomena may now be viewed as linked to the bottom-up behaviour of learners in interaction, enabled by the bottom-up effects of that interaction.

Vygotsky's focus was clearly on "the dynamic flow of the entire process of development" (ibid., p. 69; emphasis added). Although he had an open eye for the complexity involved in the very complex processes of learning and development, he shows in his work no recognition of the truly complex nature of the causal dynamics involved in the interaction within relations with peers. He did not describe the complexly generative nature of the dynamics, or the dynamic generative spaces of possibility involved (cf. Fels, 2004, p. 76). Yet, and most importantly, he did recognize very well that you 'simply' cannot explain the complexities involved from a top-down approach of science (cf. Waldrop, 1992, pp. 278-280). He knew very well that a radical new mode of thinking was needed: one, which starts from a bottom-up approach, to be taken as both process-oriented and possibility-oriented. An approach which may replace the dominant ends-oriented approach in education. An approach which is opening the future of education in the Age of Complexity, by opening new spaces of possibility, like the ZoG and SoG, as new generative spaces for education. An approach which shows how learners may achieve individual and collective generativity: by co-creating these spaces both for themselves and for the other. They may also generate their own learning and development within their SoG, through complex processes of generative change within the self-generative unit of dyadic interaction. The aim of these generative bottom-up processes is to achieve the complex capability of generativity within their own SoG: that is, the complex capability of "knowing how to go on" (Lord, 1994). This complex capability of learners, with their evolving identity, involves the question "what is this learner able to do and to be?" (Nussbaum, 2012, p. 204). Learners, then, achieving their personal identity, may be viewed as dynamic generative processes: of "knowing is doing is being" (Davis, 2004, p. 154; emphasis added). Their identity may as well be viewed as embodied in the interactivities of dynamic forms of inter-action, thriving on the connectivity of these forms (cf. Davis, 2004, p. 154). The internal capabilities of the person, generated within these dynamic forms can be taken as complex states of the person, which are fluid and dynamic (Nussbaum, 2012, p. 21; emphasis added). The complex multi-dimensional concept of 'generativity' may now be taken as representing the "combined (internal) capabilities" (p. 21; italics in original) of the person. Generativity, then, may be viewed as the complex generative motor of development: that is, the generative motor which enables the generation of complex, fluid, and dynamic states of being in learners as inherently complex human beings. This is truly opening new spaces of possibility for understanding education anew. That is, for opening the very possibility of education in the Age of Complexity. 
The link between theorizing education and theorizing development shows the very diversity of education's possibility: around what it means to educate and to be educated. This may show the unexpected and unanticipated possibilities of rethinking education. It may even show the unexpected and unanticipated possibility of reinventing education, and for the reinvention of schools (Darling-Hammond et al., 2016). Of course this may also have deep implications for the mission of education.

\section{The Mission of Education in the Age of Complexity}

All of the new thinking in complexity about the true nature of complexity, the possibility of education, and the possibility of rethinking and reinventing education, may bring us back to the basic question, about the very mission of education, about "what it means to educate and to be educated?" (Davis et al. (2004). We may now find an answer to that question from a complexified vision of complexity, based on the new paradigm of complexifying, to be taken as a complex bottom-up paradigm.

Learning and development (L\&D), as linked to interaction, may show to be inherently complex processes, showing complexities which have remained very much unknown. This demonstrates that the concept of 'development' is still very much under-theorised (Caporael et al., 2013, p. 15; cf. Nussbaum, 2012, p. 186). Because development is so closely linked to a theory of education (see Bruner, 1962, on Vygotsky's theorizing), this has serious consequences for education too. The theory of education-as-we-know-it may be viewed as a defective, incomplete theory (Nussbaum, 2012, p. 186). This theory may therefore be taken as under-theorised too! This theory 'simply' cannot afford the answer(s) to the question about the mission of education, posed by Davis et al. (2004). It cannot account for the complex multi-dimensional concept of 'generativity' as the complex, generative motor of development. It cannot account for the complex generative states of being of learners as actors in education. Henceforth, education should be taken to be much more complex than we always have taken it to be. We may take inspiration for the development of a new, (much) more complex theory of education by a new way of theorizing on development, as inspired by the work of Vygotsky. He described development as "the growing complexity of children's behaviour" (Vygotsky, 1978, p. 73). Vygotsky described the aim of L\&D for children as "to master their own behaviour, at first by external means and later by more complex inner operations" (ibid., p. 73; emphasis added). Yet, he was not able to explain the complexity involved in creating the ZPD by the child. He 'simply' lacked an adequate causal framework to do so.

The above description shows the complexity of what education may really be about in the Age of Complexity. This brings us to the more specific question "how to design education as opening the new Spaces of Generativity as being an essential part of a new possibilityoriented generative complexity approach?", and the question "how to facilitate the unlimited enlargement of possibility of the cognitive domain?" The answer to these questions may be found in a new approach, which may be described as "Imagineering education" (see Stanford University, 2014; and i.school, 2016). Imagineering education may be taken as a complexity-inspired design approach (Nijs, 2014). This is opening for a generative design of education.

The secret of the new design approach is in understanding how complexity may actually be 'at work' as generative, emergent complexity in complex processes of generative learning, enabling for so-called 'generative learning communities' (Stacey, 2014, p. 3; emphasis added). 
Mary Stacey is in our view very much right, in stating that "[T]he secret of growing a successful generative learning community is to design it" (ibid., p. 3; emphasis added). This demands, however, for new principles of organization: that is, of generative principles of organizing complexity. Principles, which are inclusive of self-organization (Cilliers, 1998, p. 103; cf. Johnson, 2001). According to Cilliers, we should be sensitive to "complex and selforganizing interactions" (p. 107; emphasis added). We also should "appreciate the play of patterns that perpetually transforms the system itself as well as the environment in which it operates" (ibid., p. 107; emphasis added; cf. Arthur, 2015, p. 25).

The above description of the link between complexity and education may lead to a deeper questioning of what is needed to conceive of the possibility of education in the Age of Complexity. This questioning may ultimately lead to the possibility of reinventing education. What is urgently needed is a way of complexifying our theorizing on education: by complexifying our theorizing of development. What is needed is a new complexified vision of complexity and education (see Fenwick, 2009, p. 112). A vision which encompasses new kinds of complexity, like generative, emergent complexity. A vision which takes education as both process-oriented and possibility-oriented. A vision which shows the very much hidden, unknown complexities involved in education, with complex unexplored possibilities, waiting to be explored in the Age of Complexity.

\section{A Complexified Vision of Education}

... all entities in the natural world, including us, are thoroughly relational beings of great complexity, who are both composed of and nested within contextual networks of dynamic and reciprocal relationships (Spretnak, 2011, p. 4; italics in original)

It will be possible now to formulate a new, so-called "complexified vision of education" (Fenwick, 2009, p. 112). A complexified vision which is enabling and inspiring for imagineering education anew in the Age of Complexity. One, which is about dynamic web-like units of learners, with their web-like relations, operating as "cooperative educational relations" (Sassone, 2002, p. 122). These relations are enabling for co-creating each other, with the complex potential of bootstrapping each other upward into each other's Space of Generativity. This possibility of bootstrapping is showing the potential of an unlimited enlargement of cognitive functioning within new spaces of possibility. This enlargement describes a complexified vision that takes Vygotsky's view about learning and development as a fundamental and foundational complex view: with learning and development as a complex, generative process of dynamic interweaving between the inter-dynamic level and the intra-dynamic level of learners involved in interaction. A generative process of dynamic interweaving, with dynamic inter- and intra-generative emergence, with its potential nonlinear effects generated over time (Jörg, 2016). This dynamic interweaving is at base of the fluid, generative processes and generative scaffolding structures that generate the complex dynamic, evolving capability of generativity. These processes are fully interconnected in a complex way (cf. Jörg, 2009, 2011, 2016). This complex process of dynamic interweaving describes the coming into being of learners as complex human beings, enabled through generative processes of becoming, being operative within web-like relations. These relations may operate as scaffolding generative relations, thereby operating as "transitional scaffolds in Vygotsky's sense" (Griesemer et al., 2014, p. 385; emphasis added). The aim of all this interweaving is the achievement of individual and collective generativity, which may operate as the generative motor of human development of the learner(s) involved, with their 
complex, dynamic, ever-evolving capabilities. The generative processes involved may operate as processes of bootstrapping: both of self-bootstrapping and of mutual bootstrapping, with both processes thriving on the full generative power of interaction (cf. Bruner, 1996; and Jörg, 2016, 2017). These complex processes are opening new Spaces of Generativity, showing trajectories of unlimited enlargement of cognitive functioning, enabling for the unexpectedly complex development of the learner, like Vygotsky's 'transitory child' (Vygotsky, 1987, p. 91; emphasis added). The child as a learner may actually become transitory by achieving generativity, individualization and literacy as complex, generative states of human being (Sassone, 1996, 2002). These generative states of being are enabling for the complex human power of "knowing how to go on" (Lord, 1994). All of this may offer a new way of thinking about the aim of education for the persons involved: that is, in terms of "knowing is doing is being" (Davis, 2004, p. 154; emphasis added). We may then finally become able to answer the fundamental question of human being as a complex question about the very complexity of human being of a person: "[W] hat is this person able to do and to be?" (Nussbaum, 2012, p. 20). This fundamental complex question links closely with the purpose of "enabling people to live full and creative lives, developing their potential" (ibid., p. 185). All of this concerns the very quality of life itself (ibid. p. 186; emphasis added).

\section{Conclusions}

All of the new thinking in complexity about the very possibility of education may result from a complexified vision, being part of and resulting from a new theoretical paradigm: the paradigm of complexifying, as a fundamental and foundational bottom-up paradigm (see Johnson, 2001, p. 67). This new paradigm is enabling for the new thinking in complexity about complexity as generative, emergent complexity. This is opening new spaces of possibility like the Zone of Generativity (Ball, 2009, 2012) and the multi-dimensional Space of Generativity (Jörg, 2016). The new theory may replace the defective, incomplete theories that still dominate policy-making (Nussbaum, 2012, p. 186), also in education.

We may now come to the conclusion that to conceive of the very possibility of education in the Age of Complexity, we urgently need a complexified vision of education, so to become able to account for the development of "the individual as a whole" (Vygotsky, 1997, p. 348): that is, as a complex whole with complex fluid, dynamic, ever-evolving capabilities (Nussbaum, 2012, p. 21). These complex capabilities may be taken to be linked with the quality of life (see Nussbaum, 2012, p. 186). From this new complexly generative perspective, based on the new paradigm of complexifying, we may better understand that complexifying the vision of education may imply the humanizing of education. The new paradigm of complexifying then may finally replace the 'blinding paradigm'; the paradigm which has made scholars blind to the problem of complexity (Morin, 2001, 2008). The paradigm that also made us blind for the 'quality of life' (Nussbaum, 2012, p. 186). Education, then, may be viewed as a complex opportunity for coming into presence as a complexly human being: that is, as "a continuation of procreation, and often a kind of beautification of it" (Sassone, 2002, p. 48; emphasis added; cf. Hansen, 2015, on education as a beautiful risk). In essence, then, education may be taken as the complex realization of the human being as a living human being (see Maturana \& Varela, 1980; and Nussbaum, 2012). This may be realized by opening and enlarging the complex spaces of the possible as complex spaces of opportunities, enabling for generativity and individualization as complex dynamic states of being; states which are ever-evolving as very complex possibilities and potentialities through generative 
processes of dynamic interweaving within the scaffolding generative relationships of selfgenerative unities of learners.

To fully understand the new complexity-inspired design approach of "Imagineering education" for complex, living human beings and their coming into presence as whole human beings, you first need to understand that "[A]ny theory of being must engage with the fact that to be a living presence is more a matter of dynamic, creative responses in webs of relationships than is a matter of categories and substances" (Spretnak, 2011, p. 55; cf. Nowotny, 2013). Based on such a theory of complex being about complex, fluid, human being, we may become able to think of a new generative, transformative pedagogy, encompassing the notion of the transformative "we" (Sassone, 2002, p. 123). That represents a new dynamic unity: the very complex, dynamic, self-generative unity. The actors in this unity may operate as a kind of 'generative bricoleurs' (Sassone, 1996, p. 520). A complex unity which encompasses transformative processes of dynamic interweaving within web-like networks and their "web dynamics" being operative within webs of "emergent dynamic relationships" (Spretnak, 2011, p. 17).

With the complexified vision of education, sketched above, we may come to the conclusion that it is possible to re-think and even to re-invent education in the Age of Complexity. We hope to have convinced the reader that it demands for a new way of thinking in complexity about the true nature of complexity, as based on a new paradigm of complexifying. The reader should, however, may also have understood that the complexity perspective, sketched above, is still very much under construction (cf. Arthur, 2015, p. 90; emphasis added), like the theory of education itself.

The new paradigm of complexifying may also be taken as opening for a new kind of theorizing pedagogy: to be taken as a generative pedagogy. One which is also foundational for a transformational pedagogy. This pedagogy can be based on a deep understanding of the very generative nature of complexity, showing its potential for enabling generative emergence and potential nonlinear emergent effects. The new paradigm of complexifying may finally make an end to the inherent trivializing of the learner in education (von Foerster, 1993). With Edgar Morin (2002), we support the view that complexifying implies a way of humanizing. This may open the humanizing of the learner as a complex human being, with the power to develop complex human capabilities through interaction with others (Nussbaum, 2012; Vygotsky, 1978). This humanizing may show the very possibility of the developing child as a complex 'transitory child' (Vygotsky, 1987, p. 91). This complex concept can be based on the understanding of the complexities involved in what Vygotsky (1978) called "transitional psychological systems" (p. 46; italics in original). The unexplored possibilities of these systems may be linked with the self-generative unity, as a complex, fluid, generative dyadic unit, described above. We may think of a complexified vision of human being as a transitory way of coming into being, enabled through generative processes of becoming self-generative within relations with others (cf. Vygotsky, 1978, p. 57). This complexity of human being may be linked with the complex capability of being self-generative, self-realizing through generative processes of becoming (cf. Maturana \& Varela, 1980; Nussbaum, 2012). That is, with the very quality of life itself (Nussbaum, 2012).

Reinventing education may now be conceived in terms of organizing generative complexity as emergent complexity, being operative in self-generative unities as transitional systems. This complexified view of education is opening new generative spaces of possibility for education. It is also opening for complexifying the learner as a complex, generative, transitory human being. These openings may show the power of new thinking in complexity 
for opening the very possibility of reinventing education. This may be opening as well the possibility of reinventing schools (Darling-Hammond et al., 2016).

\section{References}

Arthur, W. B. (2015). Complexity and the economy. Oxford: Oxford University Press.

Axelrod, R. \& Cohen, M. D. (1999). Harnessing complexity: Organizational implications of a scientific frontier. New York: The Free Press.

Ball, A. F. (2009). Improving the life course of black boys: A comprehensive model of generative change. Retrieved the 25th of April 2015 at https://www.ets.org/s/sponsored_events/achievement_gap/pdf/ball_readingtheirwaytosuccess.pdf

Ball, A. F. (2012a). To know is not enough. Presidential address at AERA 2012. Retrieved at http://www.aera.net/tabid/13250/Default.aspx

Ball, A.F. (2012b). To know is not enough : Knowledge, power, and the zone of generativity. Educational Researcher, 41(8), 283-293.

Barabási, A-L. (2003). Linked: How everything is connected to everything else and what it means for business, science, and everyday life. New York: Penguin Group.

Bohm, D. \& Peat, D. M. (2000; 2nd Ed.), Science, order, and creativity. London: Routledge

Bruner, J. (1962). Foreword. In L. Vygotsky, Thought and language (pp. v-x). MIT Press.

Bruner, J. (1987). Foreword. In R. W. Rieber \& A. S. Carton (Eds.), The collected works of L. S. Vygotsky, Vol.1, (pp. 1-16). New York: Plenum.

Bruner, J. (1996). The culture of education. Cambridge MA: Harvard University Press.

Bushe, G. R. (2013). Generative process, generative outcome: The transformational potential of appreciative inquiry. In D.L. Cooperrider, D.P. Zandee, L.N. Godwin, M. Avital\& B. Boland (Eds), Organizational generativity: The appreciative inquiry summit and a scholarship of transformation (pp. 89-113). Emerald Group Publishing Limited.

Caporael, L. R. Griesemer, J. R. and Wimsatt W. C. (Eds) (2014). Developing scaffolds in evolution, culture, and cognition: The Vienna series in theoretical biology. Cambridge (MA): MIT.

Cilliers, P. (1998). Complexity \& postmodernism: Understanding complex systems. London: Routledge.

Cilliers, P. (2013). A Crisis of knowledge: Complexity, understanding and the problem of responsible action. In: P. Derkx \& H. Kunneman (Eds), Genomics and democracy (pp. 37-59). Amsterdam \& New York: Rodopi.

Darling-Hammond, L., Ramos-Beban, Altamirano, and R. P. Hyler, M.E. (2015). Be the change: Reinventing school for student success. New York: Teacher College Press.

Davis, B., Phelps, R., and Wells, K. (2004). Complicity: An introduction and a welcome. Complicity: An International Journal of Complexity and Education, 1(1), pp. 1-7.

Fels, L. (2004). Complexity, teacher education and the restless jury: Pedagogical moments of performance. Complicity: An International Journal of Complexity and Education, 1(1), 73-98

Fenwick, T. (2009). Responsibility, complexity science and education: Dilemmas and uncertain responses. Studies in the Philosophy of Education, 28, 101-118.

Follett, M.P. (1924/1971). Creative experience. New York: Peter Smith.

Follett, M.P. (1995). The psychological foundations of business organization. In: P. Graham (Ed.), Mary Parker Follett: Prophet of management (pp. 35-65). Harvard Business School Press.

Gartner, A, Kohl, M. C. and Riessman, F. (1971). Children teach children: Learning by teaching. New York: Harper and Row Publishers.

Goldstein, J., Hazy, J. K., \& Lichtenstein, B. B. (2010). Complexity and the nexus of leadership: Leveraging nonlinear science to create ecologies of innovation. New York: Palgrave \& Macmillan.

Graham, P. (Ed.) (1995). Mary Parker Follett. Prophet of management: A celebration of writings from the 1920s. Boston: Harvard Business School Press.

Griesemer, J. R., Caporael, L. R., and Wimsatt, W. C. (2014). Developing Scaffolds. In: L. R.

Caporael, J. R. Griesemer, and W. C. Wimsatt (Eds), Developing scaffolds in evolution, culture, and cognition (pp. 363-388). Cambridge (MA): MIT Press.

Grotzer, T. (2012). Learning causality in a complex world: Understandings of consequence. Lanham: Rowman \& Littlefield Education. 
Hansen, D. T. (2015). Is education possible today? Teachers College Record, 117(8), 1-17.

Holland, J. (1995). Hidden order: How adaptation builds complexity. Helix books.

Holland, J. (1998). Emergence: From chaos to order. Cambridge: Perseus books.

Holland, J. (2014). Complexity: A very short introduction. Oxford: Oxford University Press.

i.school (2016). Imagineering education. Retrieved the 23th of May 2017 at

http://www.imagineeringschool.org/imagineering-education.html

Johnson, S. (2001). Emergence: The connected lives of ants, brains, cities, and software. New York: Touchstone.

Jöreskog, K.G. \& D. Sörbom. (1993). LISREL8: A guide to the program and applications.

Jörg, T. (2009). Thinking in complexity about learning and education: A programmatic view. Complicity, $6(1), 1-15$.

Jörg, T. (2011). New thinking in complexity for the social sciences and humanities: A generative, transdisciplinary approach. New York: Springer Publishers.

Jörg, T. (2014). The crisis of knowing in the age of complexity. In: M. E. Jennex (Ed.), Knowledge discovery, transfer, and management in the information Age (pp. 1-19). Hershey: IGIGlobal.

Jörg, T. (2016). Opening the wondrous world of the possible for education: A generative complexity approach. In: M. Koopmans \& D. Stamovlasis (Eds), Complex dynamical systems in education. Concepts, methods and applications (pp. 59-92). New York: Springer

Jörg, T. (2017). Reinventing science in the age of complexity. A generative complexity-inspired bottom-up approach. (In preparation).

Juarrero, A. (1999). Dynamics in action: Intentional behavior as a complex system. Cambridge: MIT Press.

Kauffman, S. (1993). The origins of order: Self-organization and selection in evolution. Oxford: Oxford University Press.

Kauffman, S. (2003). The adjacent possible: A talk with Stuart Kauffman. Accessible at https://www.edge.org/conversation/stuart_a_kauffman-the-adjacent-possible

Kauffman, S. A. (2009). Foreword: The open universe. In: R. Ulanowicz (2009), The third window (pp. ixxvii). West Conshohocken: Templeton Foundation Press.

Kauffman, S. A. (2013). Evolution beyond Newton, Darwin, and entailing law: The origin of complexity in the evolving biosphere. In Ch. H. Lineweaver, P. C. W. Davies, and M. Ruse (Eds), Complexity and the arrow of time (pp. 162-190). Cambridge (UK): Cambridge Press.

Keller, E. F. (1995). Reflections on gender and science. New Haven: Yale University Press.

Kelly, M., McKinley, S., and Duncan, V. (2016). Community wealth building: America's emerging assetbased approach to city economic development. Renewal: A Journal of Social Democracy, 24(2), pp. 5168. Retrieved at http://www.marjoriekelly.com/publications/articles-1/

Kuhn, T. S. (1970). The structure of scientific revolutions. Chicago: Chicago University Press.

Laughlin, R. (2005). A different universe: Reinventing physics from the bottom down. New York: Basic Books.

Lichtenstein, B. B. (2014). Generative emergence: A new discipline of organizational, entrepreneurial, and social innovation. Oxford: Oxford University Press.

Lord, B. (1994). Teacher's professional development: critical colleagueship and the role of professional communities. In N. Cobb (Ed.), The future of education (pp. 175-204). New York: College Board Publications.

Loreto, V., Servidio, V. D. P., Strogatz, S. H., and Tria, F. (2017). Dynamics on expanding spaces: Modelling the emergence of novelties. In Mirko Degli Esposti, Eduardo G Altmann, \& François Pachet (Eds.), Creativity and universality in language (pp. 59-83). New York: Springer.

Maruyama, M. (1963). The second cybernetics: Deviation-amplifying mutual causal processes. American Scientist, 5(2), 164-179.

Maruyama, M. (1968). Mutual causality in general systems. In J. H. Milsum (Ed.), Positive feedback (pp. 80100). Oxford: Pergamon Press.

Maturana, H. R. (1980). Biology of Cognition. In: Maturana, H. R. \& Varela, F. J. (1980). Autopoiesis and cognition: The realization of the living (pp. 2-58). Dordrecht: Reidel Publishing Company.

Maturana, H. R. \& Varela, F. J. (1980). Autopoiesis and cognition: The realization of the living. Dordrecht: Reidel Publishing Company. 
Milsum, J. H. (1968). Positive feedback: A general systems approach to positive / negative feedback and mutual causality. Oxford: Pergamon Press.

Morin, E. (2001). Seven complex lessons in education for the future. Paris: UNESCO Publishing.

Morin, E. (2002). A propos de la complexité. Available at: http://www.litt-and-co.org/philo.textes.htm

Morin, E. (2008). On complexity. Cresskill (NJ): Hampton Press.

Müller-Prothmann, T. (2006). Leveraging knowledge communication for innovation: Framework, methods and applications of social network analysis in research and development. London: Peter Lang.

Nijs, D. (2014). Imagineering the butterfly effect. Den Haag: Eleven International Publishing.

Nilsook, P., Utakrit, N., and Clayden, J. (2014). Imagineering in education: A framework to enhance student's performance and creativity in thinking. Educational Technology, Jan-Feb.

Nowotny, H. (2013). The embarrassment of complexity. Talk at the Peter Drucker Forum 2013. Accessed the 17th of March 2017 at https://www.druckerforum.org/blog/?p=640

Nowotny, H., Scott, P., and Gibbons, M. (2001). Re-Thinking science: Knowledge and the public in an age of uncertainty. Cambridge: Polity Press.

Nussbaum, M. (2012). Creating capabilities: The human development approach. Cambridge (MA): The Belknap Press.

Osberg, D. (2009). "Enlarging the space of the possible" around what is means to educate and be educated. Complicity: An International Journal of Complexity and Education, 6(1), iii-x.

Rescher, N. (1998). Complexity: A philosophical overview. New Brunswick: Transaction Publishers.

Sassone, L.A. (1996). Philosophy across the curriculum: A democratic Nietzschean pedagogy. Educational Theory 46 (4), 511-524.

Sassone, L.A. (2002). The process of becoming: A democratic Nietzschean philosophical pedagogy for individualization. Chicago: Discovery Association Publishing House.

Solé, R. \& Goodwin, B. (2000). Signs of life: How complexity pervades biology. New York: Basic Books.

Spretnak, Ch. (2011). Relational reality: New discoveries of interrelatedness that are transforming the modern world. Topsham (ME): Green Horizon Books.

Stacey, M. (2014). Generativity in organizational life. Available at http://www.contextconsulting.com/wpcontent/uploads/2014/03/Generativity-in-Organizational-Life-2014.pdf Stanford University (2014). Retrieved the 21th of May 2017 at http://www.imagineeringschool.org/about.html

Stepper, J. (2014). Introducing generative practice. Available at http://www.hbs.edu/faculty/Lists/Events/Attachments/881/Intro\%20to\%20Generative\%20Practices $\% 20$ CVH.pdf

Van Geert, P. (1994). Dynamic systems of development: Change between complexity and chaos. New York: Harvester Wheatsheaf.

Von Foerster. H. (1993). Understanding understanding. New York: Springer-Verlag.

Vygotsky, L. (1978). Mind in society. Cambridge MA: Harvard University Press.

Vygotsky, L. (1987). Collected works, Vol. 1: Problems of general psychology. Edited by R.W. Rieber, and A.S. Carton. New York: Plenum Press.

Vygotsky, L. (1997). Collected works, Vol. 3: Problems of the theory and history of psychology. Edited by R.W. Rieber, and J. Wollock. New York: Plenum Press.

Waldrop, M. M. (1992). Complexity: The emerging science at the edge of order and chaos. New York: A Touchstone Book.

Wallerstein I. et al. (1996). Opening the social sciences. Report of the Gulbenkian Commission on the restructuring of the social sciences. Stanford, CA: Stanford University Press.

Whitehead, N. (1978). Process and reality. New York: The Free Press.

Wink, J. \& Putney, L. (2002). A vision of Vygotsky. Boston: Allyn and Bacon.

\section{About the Author}

Ton Jörg was affiliated as educational evaluation researcher in diverse national projects in the Netherlands. In 2011, his book on New Thinking in Complexity for the Social Sciences and Humanities - A Generative, Transdisciplinary Approach was published by Springer Publishers. Recently, he published several articles with applications of his new thinking in complexity: on topics like innovation, the crisis of knowing, the management of knowledge, and the complexity of education. He is now writing a new book on The 
Reinvention of Science in the Age of Complexity, which is based on a new bottom-up paradigm of generative complexity. E-mail: agdjorg@gmail.com

(c) Copyright 2017. The author, TON JÖRG, assigns to the University of Alberta and other educational and non-profit institutions a nonexclusive license to use this document for personal use and in courses of instruction provided that the article is used in full and this copyright statement is reproduced. The authors also grant a non-exclusive license to the University of Alberta to publish this document in full on the World Wide Web, and for the document to be published on mirrors on the World Wide Web. Any other usage is prohibited without the express permission of the authors. 